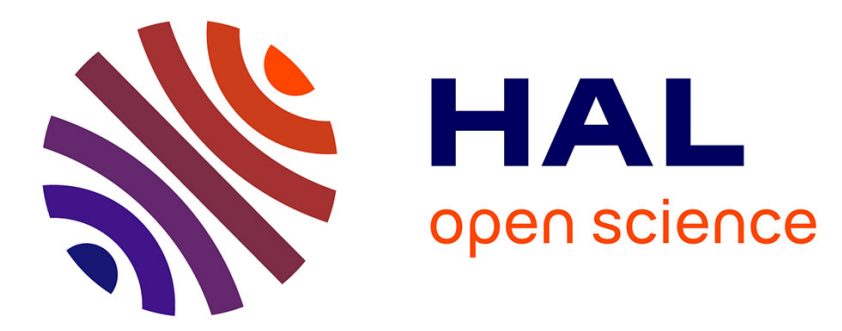

\title{
Structure Preserving Model Reduction of Low Frequency Electromagnetic Problem based on POD and DEIM
}

Laurent Montier, Antoine Pierquin, Thomas Henneron, Stéphane Clénet

\section{- To cite this version:}

Laurent Montier, Antoine Pierquin, Thomas Henneron, Stéphane Clénet. Structure Preserving Model Reduction of Low Frequency Electromagnetic Problem based on POD and DEIM. IEEE Transactions on Magnetics, 2017, 53, pp.1-4. 10.1109/TMAG.2017.2663761 . hal-01519749

\author{
HAL Id: hal-01519749 \\ https://hal.science/hal-01519749
}

Submitted on 9 May 2017

HAL is a multi-disciplinary open access archive for the deposit and dissemination of scientific research documents, whether they are published or not. The documents may come from teaching and research institutions in France or abroad, or from public or private research centers.
L'archive ouverte pluridisciplinaire HAL, est destinée au dépôt et à la diffusion de documents scientifiques de niveau recherche, publiés ou non, émanant des établissements d'enseignement et de recherche français ou étrangers, des laboratoires publics ou privés. 


\title{
Structure Preserving Model Reduction of Low Frequency Electromagnetic Problem based on POD and DEIM
}

\author{
L. Montier ${ }^{1,2}$, A. Pierquin ${ }^{1}$, T. Henneron ${ }^{1}$, and S. Clénet ${ }^{1}$ \\ ${ }^{1}$ Univ. Lille, Centrale Lille, Arts et Metiers ParisTech, HEI, EA 2697 - L2EP, F-59000 Lille, France \\ ${ }^{2}$ EDF R\&D, THEMIS, 1 Avenue du Général de Gaulle, 92140 Clamart, France
}

\begin{abstract}
The Proper Orthogonal Decomposition (POD) combined with the (Discrete) Empirical Interpolation Method (DEIM) can be used to reduce the computation time of the solution of a Finite Element (FE) model. However, it can lead to numerical instabilities. To increase the robustness, the POD_DEIM model must be constructed by preserving the structure of the full FE model. In this article, the structure preserving is applied for different potential formulations used to solve electromagnetic problems.
\end{abstract}

Index Terms - Structure preserving, Proper Orthogonal Decomposition, Discrete Empirical Interpolation Method.

\section{INTRODUCTION}

$\mathrm{T}$ O study electrical devices, the Finite Element (FE) method is often used to solve low frequency electromagnetic problems in the time or frequency domain. The computation time required to solve this kind of problems can be large due to a fine mesh, to an important number of time or frequency steps and to the nonlinear behaviour law of the ferromagnetic material. In the literature, to reduce the size of the FE model and the computation time, the Proper Orthogonal Decomposition (POD) is the most popular approach [1][2]. With a nonlinear behavior law, the POD is not so efficient due to the calculation of nonlinear terms. Then, to reduce this computation cost, interpolation methods have been developed [3-7]. The POD combined with the (Discrete) Empirical Interpolation Method (DEIM) has been used to solve a lot of problems in engineering. In electromagnetic modeling, this approach has been already applied to solve a nonlinear magnetostatic problem coupled with an electric circuit [8][9], a magneto-quasistatic problem including a motion of a subdomain [10] or a nonlinear magnetodynamic problem with a model order reduction of an adaptive subdomain [11].

To build the reduced model from the POD, the solution vector is approximated in a reduced basis deduced from the snapshot method [2]. In computational electromagnetics, potential formulations coupled with electric equations are commonly used to model a device. Different types of degree of freedom (DoF) (i.e. edges, nodes, voltages or/and currents, ...) are considered in the solution vector. Then, a reduced basis associated with each type of DoF can be defined to preserve the structure of the matrix system between the full and reduced models.
In this article, the structure preserving approach is applied for different potential formulations used to solve electromagnetic problems. The method is based on the construction of reduced basis attached to each type of DoF. Firstly, the general framework is presented. Secondly, the structure preserving is applied on the potential formulations of a nonlinear magnetostatic problem coupled with electric circuit and a magneto-quasistatic problem. Finally, the reduced models with and without the structure preserving approach are applied on academic examples. The results obtained with both types of reduced models are then compared in terms of accuracy with the full model.

\section{GeNERAL FramewORK}

The general form of the differential algebraic equations from low frequency electromagnetic problem solved by the finite element method is:

$$
\mathbf{M X}(\mathrm{t})+\mathbf{K} \frac{\mathrm{d} \mathbf{X}(\mathrm{t})}{\mathrm{dt}}=\mathbf{F}(\mathrm{t})+\mathbf{N}_{\mathrm{fp}}(\mathbf{X}(\mathrm{t}))
$$

with $\mathbf{M}$ and $\mathbf{K}$ square matrices, $\mathbf{F}(\mathrm{t})$ the source vector, $\mathbf{N}_{\mathrm{fp}}(\mathrm{t})$ the nonlinear term and $\mathbf{X}(\mathrm{t})$ the solution vector. The vector $\mathbf{X}(\mathrm{t})$ can be composed of different types of DoF. Usually, $\mathbf{X}(\mathrm{t})$ is written such as $\mathbf{X}(\mathrm{t})=\left[\mathbf{X}_{1}{ }^{\mathrm{t}}(\mathrm{t}) \mathbf{X}_{2}{ }^{\mathrm{t}}{ }^{(t)} \ldots \mathbf{X}_{\mathrm{n}}{ }^{\mathrm{t}}(\mathrm{t})\right]^{\mathrm{t}}$ with $\mathrm{n}$ the number of DoF types and $\mathbf{X}_{i}(t)$ the solution vector of the $i^{\text {th }}$ type of DoF (edges, nodes, currents, ...). For example, in the case of the A-v electric formulation coupled with electric circuits, the unknowns related to edges, nodes and currents are concatenated in $\mathbf{X}(\mathrm{t})$. By applying the POD method [1][2] combined with the DEIM approach [3-5] on a nonlinear FE model (1), the solution vector $\mathbf{X}(\mathrm{t})$ of size $\mathrm{N}_{\mathrm{t}}$ of the full problem is approximated by $\mathbf{X}(\mathrm{t})=\boldsymbol{\Psi} \mathbf{X}_{\mathrm{r}}(\mathrm{t})$ with $\mathbf{X}_{\mathrm{r}}(\mathrm{t})$ the solution vector of the reduced model of size $\mathrm{N}_{\mathrm{X}}$ and the nonlinear term is approximated by $\mathbf{N}_{\mathrm{fp}}=\mathbf{M}_{\mathrm{int}} \mathbf{N}_{\mathrm{fp}-\mathrm{m}}$. The operator $\Psi$ is deduced from the snapshot matrix $\mathbf{M}_{\mathrm{X}}$ defined by $\mathbf{M}_{\mathrm{X}}=\left(\mathbf{X}\left(\mathrm{t}_{\mathrm{j}}\right)\right)_{1 \leq j \leq \mathrm{N} s}$. This snapshot matrix is thus obtained from Ns solutions of the FE model during the first time steps or in a preprocessing step. Then, the matrix $\Psi$ is computed from the Singular Value Decomposition of $\mathbf{M}_{\mathrm{x}}$. The interpolation matrix $\mathbf{M}_{\text {int }}$ and the vector $\mathbf{N}_{\mathrm{fp}-\mathrm{m}}$ which depends on a nonlinear function are approximated by the DEIM, where $\mathbf{N}_{\mathrm{fp}-\mathrm{m}}$ corresponds to a small number of nonlinear entries of $\mathbf{N}_{\mathrm{fp}}$. Finally, the reduced model can be written: 


$$
\mathbf{M}_{\mathrm{r}} \mathbf{X}_{\mathrm{r}}(\mathrm{t})+\mathbf{K}_{\mathrm{r}} \frac{\mathrm{d} \mathbf{X}_{\mathrm{r}}(\mathrm{t})}{\mathrm{dt}}=\mathbf{F}_{\mathrm{r}}(\mathrm{t})+\mathbf{M}_{\mathrm{int}} \mathbf{N}_{\mathrm{fp}-\mathrm{m}}\left(\mathbf{X}_{\mathrm{r}}(\mathrm{t})\right)
$$

with $\mathbf{M}_{\mathrm{r}}$ and $\mathbf{K}_{\mathrm{r}} \mathrm{N}_{\mathrm{X}} \times \mathrm{N}_{\mathrm{X}}$ square matrices and $\mathbf{F}_{\mathrm{r}}(\mathrm{t})$ and $\mathbf{N}_{\mathrm{fp}-\mathrm{m}}$ vectors of size $\mathrm{N}_{\mathrm{X}}$.

If one uses directly the snapshots of vector $\mathbf{X}(\mathrm{t})$ to define $\Psi$, the robustness of the reduced model might be worsened and it can be unstable. To preserve the structure of the full FE model with the reduced model, a reduced basis attached to each type of DoF is computed. The reduced basis $\Psi_{\mathrm{i}}$ related to the $i^{\text {th }}$ type of DoF is defined from the snapshot matrix $\mathbf{M}_{\mathrm{Xi}}$ of $\mathbf{X}_{\mathrm{i}}(\mathrm{t})$. Then, we have $\mathbf{X}_{\mathrm{i}}(\mathrm{t})=\Psi_{\mathrm{i}} \mathbf{X}_{\mathrm{ri}}(\mathrm{t})$. The matrix $\Psi$ is set as a block diagonal matrix such as

$$
\mathbf{X}(\mathrm{t})=\left[\begin{array}{c}
\mathbf{X}_{1}(\mathrm{t}) \\
\vdots \\
\mathbf{X}_{\mathrm{n}}(\mathrm{t})
\end{array}\right]=\boldsymbol{\Psi} \mathbf{X}_{\mathrm{r}}(\mathrm{t})=\boldsymbol{\Psi}\left[\begin{array}{c}
\mathbf{X}_{\mathrm{r} 1}(\mathrm{t}) \\
\vdots \\
\mathbf{X}_{\mathrm{rn}}(\mathrm{t})
\end{array}\right] \text { with } \boldsymbol{\Psi}=\left[\begin{array}{ccc}
\boldsymbol{\Psi}_{1} & \ldots & \mathbf{0} \\
\vdots & \ddots & \vdots \\
\mathbf{0} & \ldots & \boldsymbol{\Psi}_{\mathrm{n}}
\end{array}\right]
$$

and the reduced problem (2) is constructed and solved.

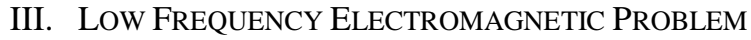

\section{A. NonLinear Magnetostatic problem coupled with Electric Equations}

We consider a domain D of boundary $\Gamma\left(\Gamma=\Gamma_{\mathrm{B}} \cup \Gamma_{\mathrm{H}}\right.$ and $\Gamma_{\mathrm{B}} \cap \Gamma_{\mathrm{H}}=0$ ) (Fig. 1). The problem is solved on $\mathrm{D} \times[0, \mathrm{~T}]$ with $\mathrm{T}$ the length of the time interval. The inductors are supposed to be stranded and the eddy current effect is neglected. For the ferromagnetic materials, the nonlinear behaviour law is considered.

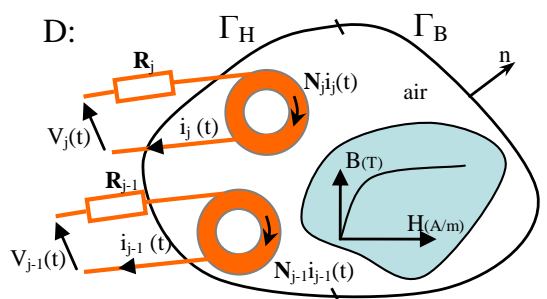

Fig. 1. Non-linear magnetostatic problem coupled with electric circuits.

In magnetostatics, the problem can be solved with the vector potential formulation. Then, the strong formulation is

$$
\begin{aligned}
& \operatorname{curl}\left(v_{\mathrm{ff}} \operatorname{curl} \mathbf{A}(\mathbf{x}, \mathrm{t})\right)-\sum_{\mathrm{j}=1}^{N_{\mathrm{st}}} \mathbf{N}_{\mathrm{j}}(\mathbf{x}) \mathrm{i}_{\mathrm{j}}(\mathrm{t})=-\operatorname{curl}\left(\mathbf{H}_{\mathrm{fp}}(\mathbf{B}(\mathbf{x}, \mathrm{t}))\right. \\
& \frac{\mathrm{d}}{\mathrm{dt}} \int_{\mathrm{D}} \mathbf{A}(\mathbf{x}, \mathrm{t}) \mathbf{N}_{\mathrm{j}}(\mathbf{x}) \mathrm{dD}+\mathrm{R}_{\mathrm{j}} \mathrm{i}_{\mathrm{j}}(\mathrm{t})=\mathrm{v}_{\mathrm{j}}(\mathrm{t}) \text { with } \mathrm{j}=1, \ldots, \mathrm{N}_{\mathrm{st}}
\end{aligned}
$$

with $\mathbf{A}$ the vector potential, $\mathbf{N}_{\mathrm{j}}, \mathrm{i}_{\mathrm{j}}$ and $\mathrm{v}_{\mathrm{j}}$ the unit current density, the current and the voltage of the $\mathrm{j}^{\mathrm{th}}$ stranded inductor respectively. $\mathrm{N}_{\mathrm{st}}$ is the number of stranded inductors, $v_{\mathrm{fp}}$ denotes a constant reluctivity and $\mathbf{H}_{\mathrm{fp}}(\mathbf{B}(\mathbf{x}, \mathrm{t}))=\left(v_{(\mathbf{B})}(\mathbf{x}) \quad-\right.$ $\left.v_{\mathrm{fp}}\right) \mathbf{B}(\mathbf{x}, \mathbf{t})$ a virtual magnetization vector depending on the nonlinear reluctivity $v_{(\mathbf{B})}(\mathbf{x})$ and on the magnetic flux density. The field $\mathbf{A}(\mathbf{x}, \mathrm{t})$ is discretised using edge elements in $3 \mathrm{D}$ and nodal elements in $2 \mathrm{D}$, while $\mathbf{N}_{\mathrm{j}}(\mathbf{x})$ is computed using facet elements [12]. We denote $A_{i}(t)$ the line integral of $\mathbf{A}$ along the $\mathrm{i}^{\text {th }}$ edge in $3 \mathrm{D}$ or the value of $\mathbf{A}$ on the $\mathrm{i}^{\text {th }}$ node in $2 \mathrm{D}$. Then, applying the FE method to (4) leads to the following system of differential algebraic equations:

$$
\begin{aligned}
& {\left[\begin{array}{cccc}
\mathbf{M}_{v_{\text {ff }}} & -\mathbf{F}_{1} & \cdots & -\mathbf{F}_{\mathrm{Nst}} \\
0 & \mathrm{R}_{1} & \cdots & 0 \\
\vdots & & \ddots & 0 \\
0 & \cdots & 0 & \mathrm{R}_{\mathrm{N}_{\mathrm{st}}}
\end{array}\right]\left[\begin{array}{c}
\mathbf{X}_{\mathrm{A}}(\mathrm{t}) \\
\mathrm{i}_{1}(\mathrm{t}) \\
\vdots \\
\mathrm{i}_{\mathrm{Nst}}(\mathrm{t})
\end{array}\right]+\left[\begin{array}{cccc}
0 & \cdots & & 0 \\
\mathbf{F}_{1}^{\mathrm{t}} & \ddots & & \vdots \\
\vdots & & \ddots & \\
\mathbf{F}_{\mathrm{N}_{\mathrm{st}}}^{\mathrm{t}} & 0 & \cdots & 0
\end{array}\right] \frac{\mathrm{d}}{\mathrm{dt}}\left[\begin{array}{c}
\mathbf{X}_{\mathrm{A}}(\mathrm{t}) \\
\mathrm{i}_{1}(\mathrm{t}) \\
\vdots \\
\mathrm{i}_{\mathrm{N}_{\mathrm{st}}}(\mathrm{t})
\end{array}\right]=} \\
& {\left[\begin{array}{c}
0 \\
\mathbf{v}_{1}(t) \\
\vdots \\
\mathbf{v}_{\mathbb{N}_{\mathrm{st}}}(\mathrm{t})
\end{array}\right]-\left[\begin{array}{c}
\mathbf{N}_{f \mathrm{fp}}\left(\mathbf{X}_{\mathrm{A}}(\mathrm{t})\right) \\
0 \\
\vdots \\
0
\end{array}\right]}
\end{aligned}
$$

where $\mathbf{X}_{\mathrm{A}}(\mathrm{t})$ is a vector such that $\left(\mathrm{X}_{\mathrm{Ai}}(\mathrm{t})\right)_{1 \leq i \leq \mathrm{Ne}}=\left(\mathrm{A}_{\mathrm{i}}(\mathrm{t})\right)_{1 \leq i \leq \mathrm{Ne}}$ and $\mathrm{N}_{\mathrm{e}}$ is the number of DoF associated with $\mathbf{X}_{\mathrm{A}}(\mathrm{t})$. $\mathbf{M}_{\mathrm{vfp}}$ is a $\mathrm{N}_{\mathrm{e}} \times \mathrm{N}_{\mathrm{e}}$ square matrix, while $\mathbf{F}(\mathrm{t})$ and $\mathbf{N}_{\mathrm{fp}}\left(\mathbf{X}_{\mathrm{A}}(\mathrm{t})\right)$ are vectors of size $\mathrm{N}_{\mathrm{e}}$. Equation (6) can be rewritten in a condensed form similar to (2) by considering that $\mathbf{X}(\mathrm{t})=\boldsymbol{\Psi} \mathbf{X}_{\mathrm{r}}(\mathrm{t})$ with:

$$
\mathbf{X}(\mathrm{t})=\left[\begin{array}{c}
\mathbf{X}_{\mathrm{A}}(\mathrm{t}) \\
\mathbf{I}(\mathrm{t})
\end{array}\right] \text { and } \Psi=\left[\begin{array}{cc}
\Psi_{\mathrm{A}} & \mathbf{0} \\
\mathbf{0} & \mathbf{I}
\end{array}\right]
$$

where $\mathbf{X}(\mathrm{t})$ is the vector of unknowns of size $\mathrm{N}_{\mathrm{t}}=\mathrm{N}_{\mathrm{e}}+\mathrm{N}_{\mathrm{st}}$, $\left(\mathrm{I}_{\mathrm{j}}(\mathrm{t})\right)_{1 \leq \mathrm{j} \leq \mathrm{Nst}}=\left(\mathrm{i}_{\mathrm{j}}(\mathrm{t})\right)_{1 \leq \mathrm{j} \leq \mathrm{Nst}}, \Psi_{\mathrm{A}}$ is the reduced basis associated with $\mathbf{X}_{\mathrm{A}}(\mathrm{t})$ and $\mathbf{I d}$ is the identity matrix of size $\mathrm{N}_{\mathrm{st}} \times \mathrm{N}_{\mathrm{st}}$. In practice, the number of stranded inductors associated with electrical devices is low. Then, it is not necessary to construct a reduced basis for the currents vector $\mathbf{I}(\mathrm{t})$.

\section{B. Magneto-quasistatic problem}

We consider a domain D of boundary $\Gamma\left(\Gamma=\Gamma_{\mathrm{B}} \cup \Gamma_{\mathrm{H}}\right.$ and $\Gamma_{\mathrm{B}} \cap \Gamma_{\mathrm{H}}=0$ ) (Fig. 2). The inductors are supposed to be stranded and the eddy current effect is taken into account in a conducting subdomain $D_{c}$ of boundary $\Gamma_{\mathrm{c}}\left(\Gamma_{\mathrm{c}}=\Gamma_{\mathrm{E}} \cup \Gamma_{\mathrm{J}}\right.$ and $\left.\Gamma_{\mathrm{E}} \cap \Gamma_{\mathrm{J}}=0\right)$. For simplify the reading, we consider only one stranded inductor and a linear behavior law for the ferromagnetic materials.

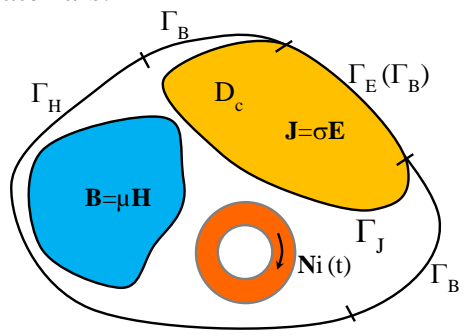

Fig. 2. Magneto-quasistatic problem.

The magneto-quasistatic problem can be solved with the following electric formulation:

$\operatorname{curl}(v \operatorname{curl} \mathbf{A}(\mathbf{x}, \mathrm{t}))+\partial_{\mathrm{t}} \mathbf{A}(\mathbf{x}, \mathrm{t})+\operatorname{\sigma grad} v(\mathbf{x}, \mathrm{t})=\mathbf{N}(\mathbf{x}) \mathrm{i}(\mathrm{t})$

$\operatorname{div}\left(\partial_{\mathrm{t}} \mathbf{A}(\mathbf{x}, \mathrm{t})+\sigma \operatorname{grad} \mathrm{v}(\mathbf{x}, \mathrm{t})\right)=0$

where $\mathbf{A}$ and $\mathbf{v}$ denote the magnetic vector potential and the electric scalar potential defined in $D_{c}, v$ and $\sigma$ are the magnetic reluctivity and the electric conductivity. The field $\mathrm{v}(\mathbf{x}, \mathrm{t})$ is discretised using nodal elements. Then, applying the FE method to (8) and (9) leads to:

$$
\left[\begin{array}{cc}
\mathbf{M}_{\mathrm{A}} & \mathbf{C}_{\mathrm{Av}} \\
0 & \mathbf{M}_{\mathrm{v}}
\end{array}\right]\left[\begin{array}{l}
\mathbf{X}_{\mathrm{A}}(\mathrm{t}) \\
\mathbf{X}_{\mathrm{v}}(\mathrm{t})
\end{array}\right]+\left[\begin{array}{cc}
\mathbf{K}_{\mathrm{A}} & 0 \\
\mathbf{C}_{\mathrm{Av}}^{\mathrm{t}} & 0
\end{array}\right] \frac{\mathrm{d}}{\mathrm{dt}}\left[\begin{array}{l}
\mathbf{X}_{\mathrm{A}}(\mathrm{t}) \\
\mathbf{X}_{\mathrm{v}}(\mathrm{t})
\end{array}\right]=\left[\begin{array}{c}
\mathbf{F}_{\mathrm{A}}(\mathrm{t}) \\
0
\end{array}\right]
$$


with $\mathbf{X}_{\mathrm{A}}(\mathrm{t})$ a vector such that $\left(\mathrm{X}_{\mathrm{Ai}}(\mathrm{t})\right)_{1 \leq \mathrm{i} \leq \mathrm{Ne}}=\left(\mathrm{A}_{\mathrm{i}}(\mathrm{t})\right)_{1 \leq \mathrm{i} \leq \mathrm{Ne}}, \mathbf{X}_{\mathrm{v}}(\mathrm{t})$ a vector such that $\left(\mathrm{X}_{\mathrm{vi}}(\mathrm{t})\right)_{1 \leq i \leq \mathrm{Nn}}=\left(\mathrm{v}_{\mathrm{i}}(\mathrm{t})\right)_{1 \leq \mathrm{i} \leq \mathrm{Nn}}$ and $\mathrm{N}_{\mathrm{n}}$ the number of DoF of v. $\mathbf{M}_{\mathrm{A}}$ and $\mathbf{K}_{\mathrm{A}}$ are $\mathrm{N}_{\mathrm{e}} \times \mathrm{N}_{\mathrm{e}}$ square matrices, $\mathbf{M}_{\mathrm{v}}$ is a $\mathrm{N}_{\mathrm{n}} \times \mathrm{N}_{\mathrm{n}}$ square matrix. $\mathbf{C}_{\mathrm{Av}}$ is a $\mathrm{N}_{\mathrm{e}} \times \mathrm{N}_{\mathrm{v}}$ matrix and $\mathbf{F}_{\mathrm{A}}$ a vector of size $\mathrm{N}_{\mathrm{e}}$. Finally, equation (10) can be rewritten in a condensed form similar to (2) (without the nonlinear term) by considering that $\mathbf{X}(\mathrm{t})=\boldsymbol{\Psi} \mathbf{X}_{\mathrm{r}}(\mathrm{t})$ with:

$$
\mathbf{X}_{(t)}=\left[\begin{array}{l}
\mathbf{X}_{\mathrm{A}}(\mathrm{t}) \\
\mathbf{X}_{\mathrm{v}}(\mathrm{t})
\end{array}\right] \text { and } \Psi=\left[\begin{array}{cc}
\Psi_{\mathrm{A}} & \mathbf{0} \\
\mathbf{0} & \Psi_{\mathrm{v}}
\end{array}\right]
$$

\section{APPLICATIONS}

\section{A. Example 1: Three phase transformer}

A 2D magnetostatic example, made of a three phase EI transformer supplied at $50 \mathrm{~Hz}$ with sinusoidal voltages, is studied (Fig. 3(a)) [13]. The nonlinear behavior of the ferromagnetic core is considered (Fig. 3(b)). The full model corresponds to the one presented in the section III-A. The number of DoF of the full system is 2073. To deduce the reduced model, an Offline/Online approach is used [8][9]. This approach is based on the expertise of the engineer. In electrical engineering, typical test procedures are used to determine parameters of equivalent circuit models which describes the behavior of the device on the whole range of operation. Then, the idea is to consider the same approach to construct a reduced model of a FE model. We apply the POD by combining the snapshots obtained by simulating the typical test procedures. For the Offline step, to deduce the reduced models, test procedures at no load and in short-circuit are simulated on the first period of voltages with 40 time steps. The snapshots are merged in the same snapshot matrix in order to define the reduced basis. The size of the reduced models is 41. For the Online step, the evolutions of the primary currents obtained from the reduced models with and without the structure preserving and from the full model are compared. Fig. 4, 5 and 6 present the currents associated with two primary windings versus the time on several periods for the simulations at no load, in short-circuit and for a resistive load coupled with the secondary windings. We can observe that the evolutions of the currents are more accurate with the structure preserving reduced model than those from the reduced model without the structure preserving. The differences of the results from both reduced models are most significant when the saturation of the ferromagnetic core is high (Fig. 4 and 6).

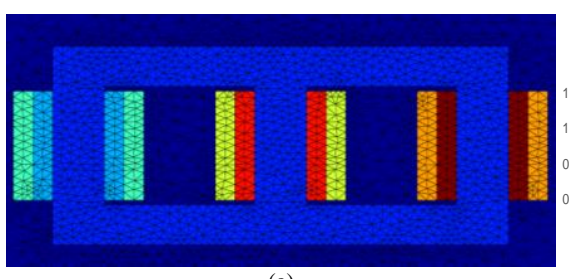

(a)

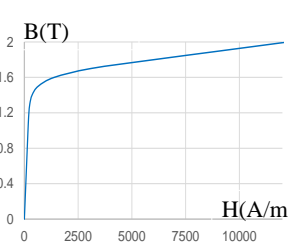

(b)
Fig. 3. (a) 2D three phase EI transformer, (b) $\mathrm{B}(\mathrm{H})$ curve of the magnetic core.

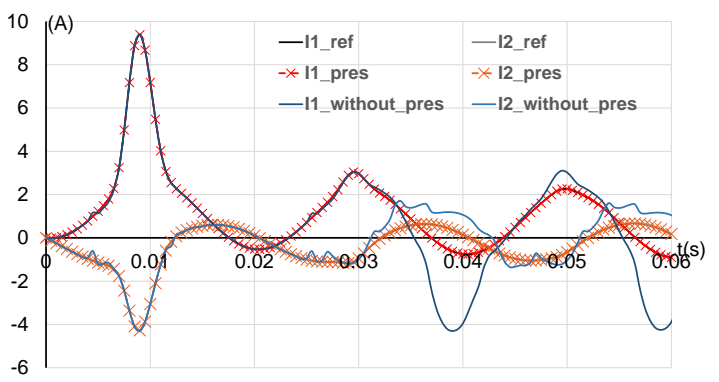

Fig. 4. Evolutions of the current associated with two primary windings at no load.

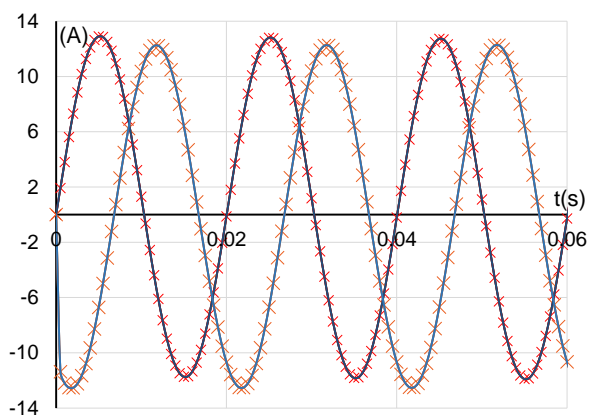

Fig. 5. Evolutions of the current associated with two primary windings in short circuit.

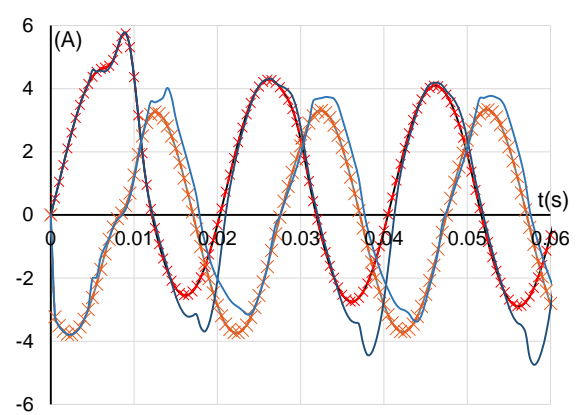

Fig. 6. Evolutions of the current associated with two primary windings for resistor load $(\mathrm{R}=200 \Omega)$.

\section{B. Example 2: Stranded inductor and two conducting plates}

A 3D magneto-quasistatic example, made of two conducting plates and a stranded inductor supplied by a sinusoidal current, is studied (Fig. 7). The problem is solved in the frequency domain. The full model is presented in the section III-B. Nevertheless, we consider the problem in the frequency domain, the number of DoF is 298867 . We study the evolution of the Joule losses versus the frequency obtained from the reduced models with and without the structure preserving approach and from the full model. During the Offline step, we consider a logarithm distribution of snapshots on the frequency interval $[50 ; 2.5 \mathrm{k}] \mathrm{Hz}$ in order to deduce the reduced models. During the Online step, the number of frequency steps is 40 with a logarithm distribution. Fig 8. presents the evolution of the Joule losses computed with the full model. Fig. 9 gives the curves of the error versus the number of snapshots for the reduced models. We can observe that the error associated with the structure preserving reduced model is always smaller than the one from the reduced model without the preserving structure. When the number of snapshots increases, the error curves of both reduced models converge toward the same error. In term of local quantity, Fig. 10 presents the distribution of the eddy current density in a 
conducting plate calculated with the full model for $\mathrm{f}=1 \mathrm{kHz}$. The error distributions of the eddy current density between the full model and both reduced models are presented in Fig. 11. The maximal error of the structure preserving reduced model is smaller than the one of the reduced model without structure preserving approach. The most significant difference between the error distributions of the two reduced models is located on the boundary $\Gamma_{\mathrm{J}}$ of the conducting plates. In fact, without the structure preserving, supplementary coupling terms between the magnetic vector potential and the electric scalar potential defined in $D_{c}$ are introduced by the matrix $\Psi$. These terms influence the boundary condition $\Gamma_{\mathrm{J}}$ where the condition $\mathbf{J} . \mathbf{n}=0$ is weakly imposed.

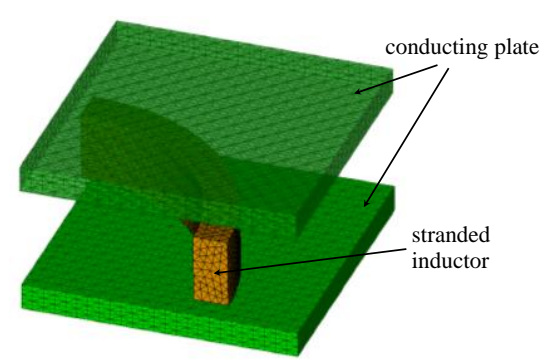

Fig. 7. Stranded inductor and two conducting plates.

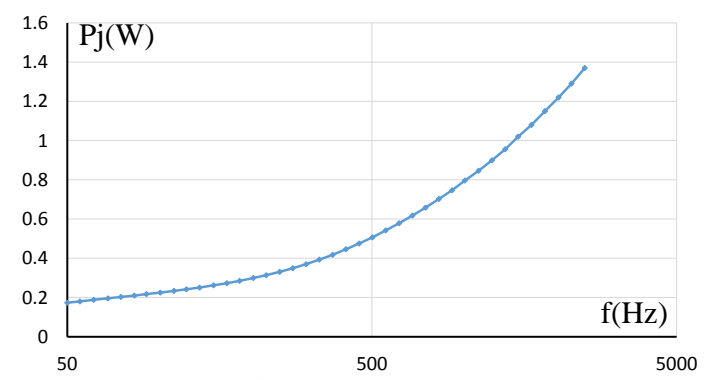

Fig. 8. Joule Losses versus the frequency.

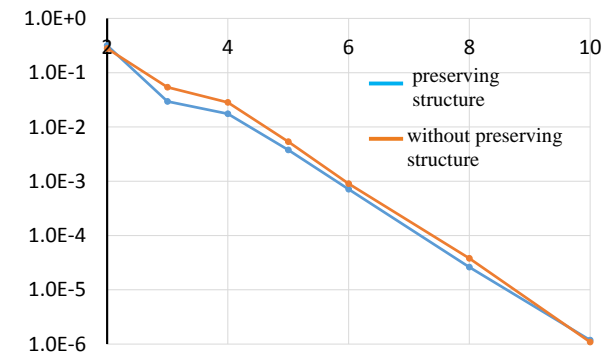

Fig. 9. Error versus the number of snapshots.

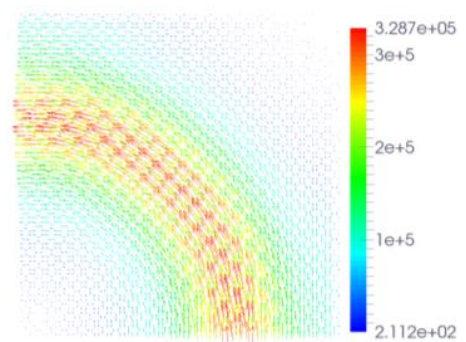

Fig. 10. Distribution of the eddy current density $\left(\mathrm{A} / \mathrm{m}^{2}\right)$ in a conducting plate.

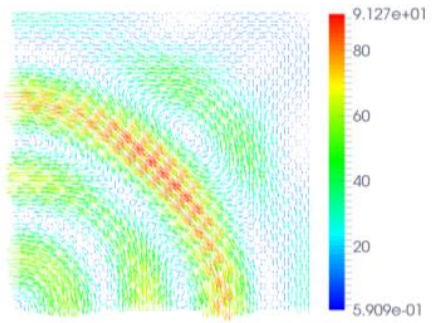

(a)

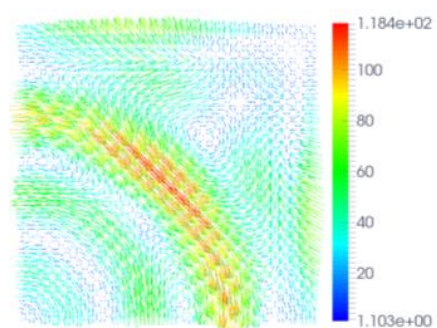

(b)
Fig. 11. Error of the eddy current density between the full model and both reduced models ((a) with the structure preserving and (b) without the structure preserving).

\section{CONCLUSION}

A structure preserving approach has been applied to the reduced models based on the potential formulations used to solve low frequency electromagnetic problems. To construct the reduced models, the POD combined with the DEIM has been used. With the studied examples, it seems that the reduced models with the structure preserving are more accurate in term of local and global quantities than those without the structure preserving.

\section{REFERENCES}

[1] J. Lumley, "The structure of inhomogeneous turbulence", Atmospheric Turbulence and Wave Propagation. A.M. Yaglom and V.I. Tatarski., pp. 221-227, 1967.

[2] L. Sirovich, "Turbulence and the dynamics of coherent structures", $Q$. Appl. Math., vol. XLV, no. 3, pp. 561-590, 1987.

[3] M. Barrault, N. C. Nguyen, Y. Maday, and A. T. Patera. "An "empirical interpolation"method: Application to efficient reduced-basis discretization of partial differential equations", C. R. Acad. Sci. Paris, vol. 339(9), 2004, pp. 667-672, 2004.

[4] S. Chaturantabut and D. C. Sorensen, "Nonlinear Model Reduction via Discrete Empirical Interpolation", SIAM J. Sci. Comput., vol. 32(5), pp. 2737-2764, 2010

[5] D. Galbally, K. Fidkowski, K. Willcox and O. Ghattas, "Non-linear model reduction for uncertainty quantification in large-scale inverse problems", Int. J. Numer. Meth. Engng., vol. 81(12) pp. 1581-1608. doi:10.1002/nme.2746 (2010).

[6] G. Dimitriu, R. Stefanescu, and I. M Navon, "Comparative numerical analysis using reduced-order modeling strategies for nonlinear largescale systems“, Journal of Computational and Applied Mathematics, vol. 310, pp. 32-43, 2017.

[7] N.C. Nguyen, A.T. Patera and J. Peraire, "A 'best points' interpolation method for efficient approximation of parametrized functions", Numerical Methods in Engineering, vol. 73(4), pp. 521-543, 2008.

[8] T. Henneron and S. Clénet, "Model-Order Reduction of Multiple-Input Non-Linear Systems Based on POD and DEI Methods", IEEE Trans. Mag., vol. 51(3), 2015.

[9] L. Montier, T. Henneron, S. Clénet and B. Goursaud "Transient simulation of an electrical rotating machine achieved through model order reduction", Advanced Modeling and Simulation in Engineering Sciences, Vol. 3, N ${ }^{\circ}$. 10, 03/2016.

[10] D. Klis, O. Farle and R. Dyczij-Edlinger, "Model-Order Reduction for the Finite-Element Boundary-Element Simulation of Eddy-Current Problems Including Rigid Body Motion", IEEE Trans. Mag., 7200404, vol. 52(3), 2016.

[11] Y. Sato, M. Clemens and H. Igarashi, "Adaptive Subdomain Model Order Reduction With Discrete Empirical Interpolation Method for Nonlinear Magneto-Quasi-Static Problems", IEEE Trans. Mag., 1100204, vol. 52(3), 2016.

[12] A. Bossavit, "A rationale for edge-elements in 3-D fields computations", IEEE Trans. Magn., vol. 24(1), pp 74-79, 1988.

[13] T. Henneron and S. Clénet, "Model Order Reduction of Non-Linear Magnetostatic Problems Based on POD and DEI Methods", IEEE Trans. Magn., vol. 50(2), 7000604, 2014. 